\title{
The Efficacy and Safety of Low Dose Epidural Butorphanol on Postoperative Analgesia following Cesarean Delivery
}

\author{
Pokharel K, ${ }^{1}$ Rahman TR, ${ }^{1}$ Singh SN, ${ }^{1}$ Bhattarai B, ${ }^{1}$ Basnet $N^{2}{ }^{2}$ Khaniya $S^{3}$ \\ 'Department of Anesthesiology and Critical Care, ${ }^{2}$ Department of Obstetrics and Gynaecology, ${ }^{3}$ Department of Surgery, BPKIHS, \\ Dharan, Nepal
}

\section{ABSTRACT}

Butorphanol is considered an effective and safe analgesic after cesarean delivery but is associated with profound dose-dependent sedation. Somnolence may cause hindrance in early mother-baby interaction. This study was designed to assess the analgesic efficacy and to monitor side-effects of low doses $(0.5 \mathrm{mg}$ and $0.75 \mathrm{mg}$ ) of epidural butorphanol with bupivacaine compared to bupivacaine alone in parturients following cesarean delivery. One hundred and twenty parturients (American Society of Anesthesiologists physical status 1 and 2) undergoing cesarean delivery were allocated into three groups: group 1 received epidural $0.125 \%$ bupivacaine while group 2 and 3 received an additional $0.5 \mathrm{mg}$ and $0.75 \mathrm{mg}$ butorphanol respectively. A combined spinal, epidural technique was used. Spinal anaesthesia was used for surgery. The epidural route was used for postoperative analgesia with the study drug. Onset, duration and quality of analgesia, lowest visual analogue scales (VAS) score, and side effects were noted. The onset and duration of analgesia in group 2 (4.1 $\pm 2.6 \mathrm{~min}$ and $202.4 \pm 62.8 \mathrm{~min})$ and group $3(4.0 \pm 2.5 \mathrm{~min}$ and $192.3 \pm 69.1 \mathrm{~min})$ were significantly different $(\mathrm{P}<0.01)$ from group $1(6.6 \pm 2.7 \mathrm{~min}$ and $145.7 \pm 89.6 \mathrm{~min})$. The quality of analgesia in terms of time to first independent movement and satisfactory VAS were statistically better $(\mathrm{P}<0.01)$ in group $2(3.9 \pm 0.3$ hour and $8.1 \pm 0.1 \mathrm{~mm})$ and group $3(3.8 \pm 0.4$ hour and $8.1 \pm 0.9 \mathrm{~mm})$ than in group $1(5.2 \pm 0.4$ hour and $6.3 \pm 1.3 \mathrm{~mm}$ ). The incidence of sedation was $5 \%$ in all the three groups. A lower dose of epidural butorphanol with bupivacaine produces a significantly earlier onset, longer duration and better quality of analgesia than bupivacaine does.

\author{
Correspondence: \\ Dr. Krishna Pokharel \\ Department of Anesthesiology and Critical Care \\ BPKIHS, Dharan, Nepal \\ E-mail: krishnadoc@yahoo.co.in
}


Pokharel et al. Low Dose Epidural Butorphanol for Postcesarean Analgesia

\section{INTRODUCTION}

The need for early ambulation for caring of the neonate by mothers makes postoperative pain management after cesarean delivery unique. To achieve this, various drug combinations and techniques have been tried to find out the more effective and safer analgesia. Butorphanol is considered effective and safe after cesarean delivery with minimal effect on the fetus, and the newborn. ${ }^{1-4}$ Further, the American Academy of Pediatrics Committee on Drugs has categorized butorphanol as compatible with breast feeding. ${ }^{5}$ However, butorphanol is associated with profound dose-dependent sedation with reported somnolence in more than $50 \%$ of patients at doses 2 mg or more. ${ }^{6}$ As somnolence can hinder early mother baby interaction, the use of butorphanol in new mothers has been criticized. ${ }^{7}$ However, analgesic effectiveness, safety and side effects including sedation by lower dose $(<1 \mathrm{mg}$ ) epidural butorphanol in mothers after cesarean delivery has not been described yet. This prospective, double-blind, randomized and controlled trial was designed to assess the analgesic efficacy and side effects of low-dose $(0.5 \mathrm{mg}$ and $0.75 \mathrm{mg}$ ) epidural butorphanol with bupivacaine in comparison to bupivacaine alone in parturients following cesarean delivery.

\section{MATERIAL AND METHODS}

This study was conducted in a university hospital for a period of nine months. One hundred and twenty consecutive parturients belonging to American Society of Anesthesiologists physical status 1 and 2 undergoing elective/emergency lower segment cesarean section were enrolled. Patients with complicated pregnancy, acute fetal distress, history of hypersensitivity to opioids/local anaesthetics were excluded.

In the preanaesthetic visit, all the patients were made familiar with the study plan and the different visual analogue scales (VAS) to be used in the assessment by the investigators. Respiratory rate, arterial blood pressure, peripheral arterial saturation and heart rate were monitored throughout the perioperative period. Spinal anesthesia was used for surgery. Epidural route was used for postoperative analgesia. If the subarachnoid block failed, the epidural route was used for anesthesia and the patient was excluded from the study. Opioid was not administered during the intraoperative period.

The patients were classed into three groups by a computer-generated method. Group 1 received epidural $0.125 \%$ bupivacaine while group 2 and 3 received an additional $0.5 \mathrm{mg}$ and $0.75 \mathrm{mg}$ butorphanol respectively. Pain score was observed at 15 min intervals on a 100 mm VAS ('no pain' at $0 \mathrm{~mm}$ end and 'worst pain ever' at $100 \mathrm{~mm}$ end). When the pain score was $40 \mathrm{~mm}$ or more, or if the patient requested analgesia (whichever occurred earlier) $10 \mathrm{ml}$ of $0.125 \%$ bupivacaine without any butorphanol in group 1, and with $0.5 \mathrm{mg}$ and $0.75 \mathrm{mg}$ butorphanol in group 2 and 3 respectively was given epidurally. The observer assessing pain was kept blinded for the epidural medication. Thereafter, continuous measurement of pain by VAS was made every two minutes till the patient was completely free of pain (VAS 0). If the VAS score failed to decline at least by the first $10 \mathrm{~mm}$ even after $30 \mathrm{~min}$ of epidural injection, the patient was given intramuscular diclofenac sodium $75 \mathrm{mg}$ and was excluded from the study.

The onset of analgesia was defined as the time from injection of the study medication to first reduction in pain intensity by at least $10 \mathrm{~mm}$ in VAS; the onset of peak analgesia was defined as the time to achieve the lowest VAS score; and the duration of analgesia was defined as the time between the onset of analgesia and either a return to baseline VAS or the time when additional pain medication was requested, whichever occurred first. The quality of analgesia was assessed based on the overall satisfaction of the patient and the time of the first changing of positions side to side independently in the bed. The overall satisfaction of the patient was assessed with a $10 \mathrm{~cm}$ scale of VAS Satisfaction ('no satisfaction' at $0 \mathrm{~cm}$ end and 'the best satisfaction' at $10 \mathrm{~cm}$ end).

Sedation was assessed when the VAS score reached the minimum (0: awake, 1: drowsy but arousable, 2: sleeping, and 3: unarousable). ${ }^{8}$ The occurrence of nausea and vomiting, pruritus, shivering and respiratory depression (respiratory rate $<12$ /minute) was noted up to 24 hours following administration of the study medication.

Approval for study was obtained from the ethics committee of the hospital and written, informed consent from each patient, before the study. The collected data was analyzed using the Statistical Package for Social Science (version 10.0 for Windows, SPSS). Analysis of variances (ANOVA) was used for comparison of mean values between more than two groups; Chi square test was used to compare the discrete variables between groups. A $p$ value of $<0.05$ was considered significant.

\section{RESULTS}

The data of only 117 patients were included for calculation because three patients were dropped from the study as their VAS score failed to decrease by at least $10 \mathrm{~mm}$ even after 30 minutes of drug administration.

There was no statistically significant difference in demographic parameters (age, height, weight) (Table 1) and duration of surgery in the three groups. The mean 
Pokharel et al. Low Dose Epidural Butorphanol for Postcesarean Analgesia

Table 1. Demographic Profiles of the Patients

\begin{tabular}{lllll}
\hline & \multicolumn{1}{c}{$\begin{array}{c}\text { Group1 } \\
(\mathbf{N}=39)\end{array}$} & \multicolumn{1}{c}{$\begin{array}{c}\text { Group 2 } \\
(\mathbf{N}=\mathbf{4 0})\end{array}$} & $\begin{array}{c}\text { Group 3 } \\
\text { (N=38) }\end{array}$ & P value \\
\hline Age (years) & $27.7 \pm 4.9(14-37)$ & $25.6 \pm 3.8(20-35)$ & $25.3 \pm 3.5(19-35)$ & NS \\
Height $(\mathrm{cm})$ & $152.2 \pm 1.2(135-171)$ & $153.5 \pm 1.4(135-187)$ & $152.9 \pm 1.8(144-167)$ & NS \\
Weight $(\mathrm{kg})$ & $62.5 \pm 11.0(34-80)$ & $62.4 \pm 9.5(30-86)$ & $60.9 \pm 9.0(47-85)$ & NS \\
\hline
\end{tabular}

onsets of analgesia and times to reach peak analgesia were significantly shorter while the mean durations of analgesia were significantly longer in the groups receiving butorphanol than in the group receiving bupivacaine alone (Figures 1a-1c). However, there is no statistical significance between group 2 and group 3 regarding onset, peak and duration of analgesia. The mean time to first independent side to side movement was significantly earlier (Figure 2a) and mean VAS satisfactions was significantly higher (Figure 2b) in the groups receiving butorphanol than in the group receiving bupivacaine alone. Similarly, there was no statistical difference between the two groups getting different doses of additional butorphanol.

Out of 117 patients, 111 (94.9\%) were "awake," 4 $(3.4 \%)$ were "drowsy but arousable" and $2(1.7 \%)$ "sleeping". No patient was "unarousable". The incidence of sedation was around $5 \%$ in all the three groups (Table 2). None of the patients developed nausea and vomiting, pruritis, shivering or respiratory depression.

Comparison of a) onset of analgesia, b) onset of peak analgesia and c) duration of analgesia. Values are expressed in Mean \pm SD (Confidence Interval 5-95\%) (Figure 1).

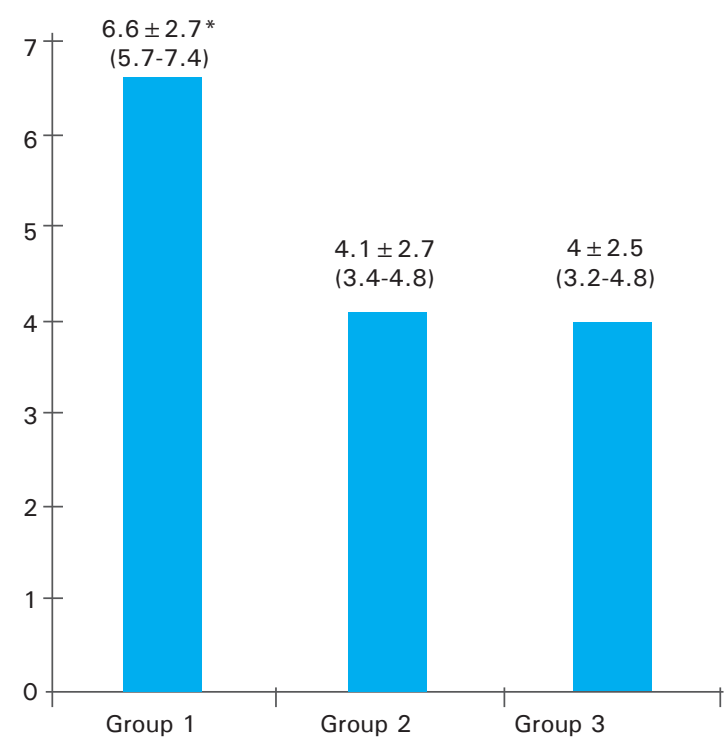

Figure 1a. Time in Minutes vs Groups
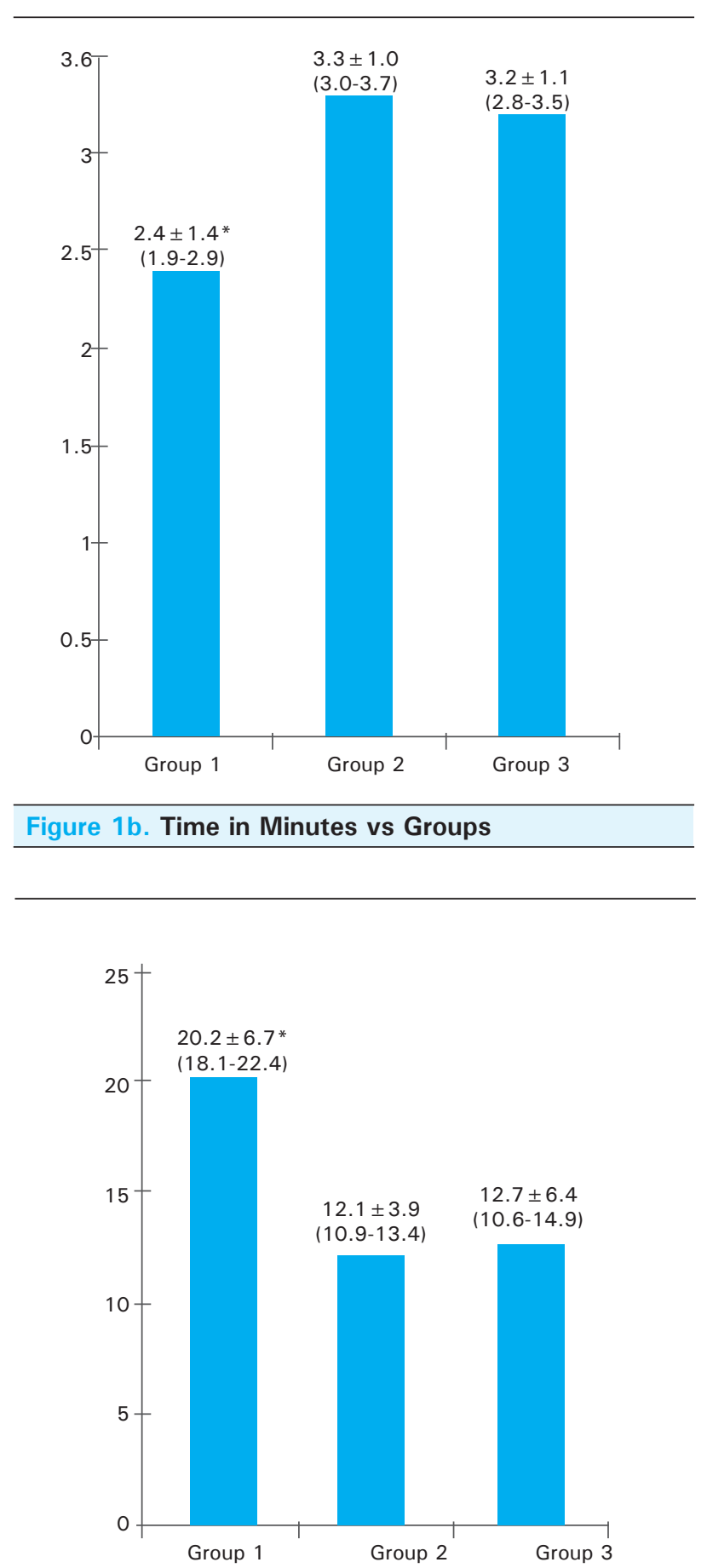

Figure 1c. Time in Hours vs Groups

JNMA || VOL 47 | NO. 2 | ISSUE 170 || APR-JUN, 2008 
Pokharel et al. Low Dose Epidural Butorphanol for Postcesarean Analgesia

Comparison of quality of analgesia in terms of a) Time to first independent change in position, b) Satisfaction VAS. Values are expressed in Mean \pm SD (confidence interval 5-95\%) [*P<0.001] (Figure 2).

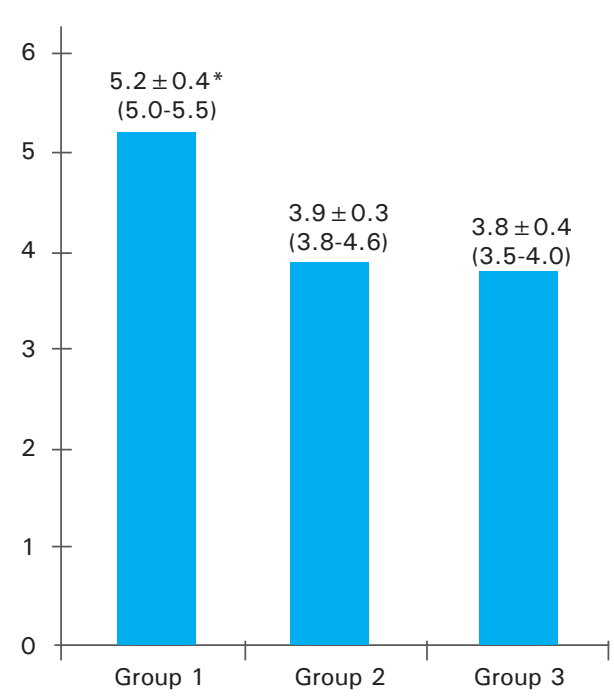

Figure 2a. Time in Hours vs Groups

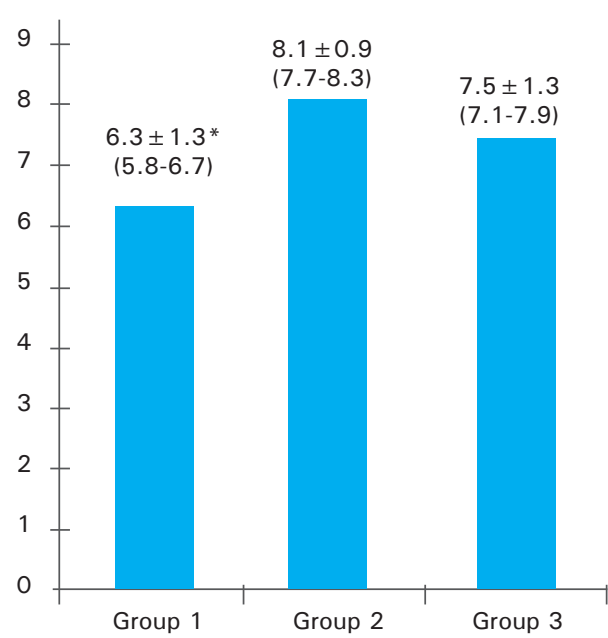

Figure 2b. Satisfaction VAS vs Groups

Table 2. Comparison of Incidence of Sedation Values are expressed in number of patients $(\%)$

\begin{tabular}{lccl}
\hline & Awake & Sedated & P value \\
\hline $\begin{array}{l}\text { GROUP 1 } \\
\text { (N = 39) }\end{array}$ & $37(94.9 \%)$ & $2(5.1 \%)$ & \\
$\begin{array}{l}\text { GROUP 2 } \\
\text { (N }=40)\end{array}$ & $38(95 \%)$ & $2(5 \%)$ & \\
$\begin{array}{l}\text { GROUP 3 } \\
\text { (N = 38) }\end{array}$ & $36(94.7 \%)$ & $2(5.3 \%)$ & 0.9 \\
TOTAL & $111(94.9 \%)$ & $6(5.1 \%)$ & \\
\hline
\end{tabular}

\section{DISCUSSION}

This study has demonstrated that the lower doses $(0.5 \mathrm{mg}$ and $0.75 \mathrm{mg}$ ) of butorphanol in addition to bupivacaine produce earlier onset and longer duration of analgesia along with better patient satisfaction. We had to exclude three patients from the study due to lack of effect of epidural injection and we attribute this failure to the malposition of the epidural catheter. Our study has shown that an addition of $0.5 \mathrm{mg}$ and $0.75 \mathrm{mg}$ of butorphanol to $0.125 \%$ bupivacaine for postcesarean analgesia decreases the time of onset of analgesia by a factor of more than 0.3 . In addition, it prolongs the duration of effective analgesia by almost a similar factor. Our finding has once again confirmed that combination of an opioid and a local anesthetic enhances the onset and prolongs the duration of analgesia more than the opioid or the local anesthetic alone. ${ }^{9,10}$ However, further work is needed to decide whether $0.5 \mathrm{mg}$ or $0.75 \mathrm{mg}$ is best suited for our patients.

Abboud and coworkers using higher doses of butorphanol ( 1 to $4 \mathrm{mg}$ ) alone epidurally observed complete pain relief in $22 \pm 2.4$ minutes which is comparable to that of our control group but remarkably longer than that of our combination group. ${ }^{11}$ Using butorphanol alone epidurally in doses 1 to $4 \mathrm{mg}$, investigators have demonstrated varying durations of pain relief ranging from 2.5 to 9 hours. ${ }^{1,6,11}$ As one can expect with the use of lower doses of butorphanol, the duration of pain relief in our study falls on the lower side of the reported range. But with the epidural catheter in place, a shorter duration of analgesia may not be a clinical disadvantage.

Our study has demonstrated that butorphanol produces a better quality of analgesia in terms of VAS Satisfaction and time to first independent movement. Abboud and coworkers also found significantly better quality of analgesia in parturients receiving epidural bupivacaine with butorphanol than with bupivacaine alone. ${ }^{1}$ A recent study has shown that $2 \mathrm{mg}$ of epidural butorphanol added to a lower concentration of bupivacaine $(0.1 \%)$ provided a better quality of labor analgesia in terms of incidence of motor blockade than $0.25 \%$ bupivacaine alone. ${ }^{12}$ Further, investigators have also found that analgesia provided by butorphanol has significant correlation with affective domain, with greater reduction in affective magnitude than pain intensity. ${ }^{13}$

The incidence of somnolence was low and similar in all the three groups in our study. Moreover, all the patients were easily arousable. The contribution of factors such as sleep deprivation, exhaustion and anxiety during labor in rendering the patients drowsy or sleepy cannot be denied. In contrast to our findings, very high incidence of somnolence has been reported with higher doses of epidural butorphanol in post-cesarean patients. ${ }^{6,14}$ 
Pokharel et al. Low Dose Epidural Butorphanol for Postcesarean Analgesia

In our study, we did not observe nausea and vomiting, pruritus, shivering and respiratory depression in any patient. Other studies of epidural butorphanol for postcesarean analgesia have also reported either a complete absence or a very low incidence of such side effects. ${ }^{1,6,11}$ In fact, prophylactic administration of butorphanol has been recommended for prevention of such side effects produced by pure agonist opioids like morphine and it has also been effectively used for the treatment of intractable pruritis associated with dermatological conditions. ${ }^{15-17}$ Further routine administration of prophylactic metoclopromide in obstetric patients contributes in decreasing the incidence of nausea and vomiting.

One limitation of our study is that we used respiratory rate alone to assess respiratory depression which may not be a sole indicator of respiratory depression. Abboud et al. have reported a decrease in the central respiratory sensitivity to $\mathrm{CO}_{2}$ lasting for 6 to 12 hours after 1.5 hours of epidural butorphanol administration. ${ }^{11}$
The rapid onset and short duration of analgesia and lack of side effects with lower doses of epidural butorphanol combined with bupivacaine in our study suggests that the drug may be particularly useful in situations where a prompt onset and/or limited duration of analgesia is indicated, patient-controlled epidural analgesia is used and side effects like sedation are not desirable.

\section{CONCLUSION}

Lower doses of epidural butorphanol combined with bupivacaine produces significantly earlier onset, longer duration and better quality of analgesia than bupivacaine alone and is safe in parturients.

\section{ACKNOWLEDGEMENT}

The authors thank Mr. Ishwori Poudyal, Department of Community Medicine, BPKIHS, for his help in statistically analyzing the data. The study was carried out with the departmental resources.

\section{REFERENCES}

1. Abboud TK, Afrasiabi A, Zhu J, Mantilla M, Reyes A, D'Onofrio L, et al. Epidural morphine or butorphanol augments bupivacaine analgesia during labor. Reg Anesth 1989;14:115-20.

2. Abboud TK, Zhu J, Afrasiabi A, Reyes A, Sherman G, Khan $\mathrm{R}$, et al. Epidural butorphanol augments lidocaine sensory anesthesia during labor. Reg Anesth 1991;16:265-7.

3. Rodriguez J, Abboud TK, Reyes A, Payne M, Zhu J, Steffens $Z$, et al. Continuous infusion epidural anesthesia during labor: A randomized, double-blind comparison of $0.0625 \%$ bupivacaine/ $0.002 \%$ butorphanol and $0.125 \%$ bupivacaine. Reg Anesth 1990;15:300-3.

4. St Amant MS, Koffel B, Malinow AM. The effects of epidural opioids on fetal heart rate variability when coadministered with $0.25 \%$ bupivacaine for labor analgesia. Am J Perinatol 1998;15(6):351-6.

5. American Academy of Pediatrics, Committee on drugs. The transfer of drugs and other chemicals into human milk. Pediatrics. 2001;108:776-89.

6. Naulty JS, Weintraub S, Mcmahon J, Ostheimer GW, Hunt C, Chantigian R. Epidural butorphanol for post cesarean delivery pain management. Anesthesiology 1984;61:A415.

7. Ayoub CM, Sinatra RS. Postoperative analgesia: epidural and spinal techniques. In: Chestnut DH, Andjelkovic N, Morrissey D, editors. Obstetric anesthesia: principles and practice: 3rd ed. Philadelphia: Elsevier Mosby; 2004. p. 479.

8. Camann WR, Hurley RH, Gilbertson LI, Long ML, Mary L, Datta S. Epidural nalbuphine for analgesia following cesarean delivery a dose response and effect of local anaesthetic choice. Can J Anaesth 1991;38:728-32.

9. Hunt CO, Naulty JS, Malinow AM, Datta S, Ostheimer GW.
Epidural butorphanol-bupivacaine for analgesia during labor and delivery. Anesth Analg 1989;68:323-7.

10. Juneja M, Ackerman WE 3rd, Heine MF, Cases-Cristobal V, Urella RP, Rigor BM. Butorphanol for the relief of shivering associated with extradural anesthesia in parturients. J Clin Anesth 1992;4:390-3.

11. Abboud TK, Moore M, Zhu H, Murakawa K, Minehart M, Longhitano $\mathrm{M}$, et al. Epidural butorphanol or morphine for the relief of post cesarean section pain: ventilatory responses to carbon dioxide. Anesth Analg 1987;66:887-93.

12. Shrestha CK, Sharma KR, Shrestha RR. Comparative study of epidural administration of $10 \mathrm{ml}$ of $0.1 \%$ bupivacaine with $2 \mathrm{mg}$ butorphanol and $10 \mathrm{ml}$ of $0.25 \%$ plain bupivacaine for analgesia during labor. J Nepal Med Assoc 2007;46:1-6.

13. Nelson KE, Eisenach JC. Intravenous butorphanol, meperidine, and their combination relieve pain and distress in women in labor. Anesthesiology 2005; 102:1008-13.

14. Palacios QT, Jones MM, Hawkins JL, Adenwala JN, Longmire S, Hess KR, et al. Post cesarean section analgesia: a comparison of epidural butorphanol and morphine. Can J Anaesth1991;38:24-30.

15. Lawhorn CD, McNitt JD, Fibuch EE, Joyce JT, Leadley RJ Jr. Epidural morphine with butorphanol for postoperative analgesia after cesarean delivery. Anesth Analg 1991;72:53-7.

16. Wittels B, Glosten B, Faure EA, Moawad AH, Ismail M, Hibbard J, et al. Opioid antagonist adjuncts to epidural morphine for postcesarean analgesia: Maternal outcomes. Anesth Analg 1993;77:925-32.

17. Dawn AG, Yosipovitch G. Butorphanol for treatment of intractable pruritus. J Am Acad Dermatol. 2006;54:527-31. 